www.jmscr.igmpublication.org Impact Factor 5.244

Index Copernicus Value: 83.27 ISSN (e)-2347-176x ISSN (p) 2455-0450 crossref DOI: https://dx.doi.org/10.18535/jmscr/v5i1.12

\title{
To Compare the Risk of Maternal and Perinatal Morbidity and Mortality in Second Gravida Women
}

\author{
Authors \\ Dr. Anjum Ara, Dr. Suman Budania \\ ${ }^{1}$ M.B.B.S, MS (Obs \& amp; Gynae), Medical Officer, CHC, Bijolia, Dist-Bhilwara, Rajasthan \\ Email: ansarkhan753@gmail.com,Phoneno.9828498753 \\ ${ }^{2}$ Asst. Professor, Dept. of Obstetrics \& Gynaecology, S.P medical College, Bikaner, Rajasthan \\ Corresponding Author \\ Dr. Suman Budania \\ Asst. Professor, Dept. of Obstetrics \& Gynaecology, S.P medical College, Bikaner, Rajasthan \\ Email:dr.budsum@gmail.com, Mobileno.:07597250555
}

\begin{abstract}
ABSTRAC
OBJECTIVES: To assess and compare obstetrical outcomes after cesarean versus vaginal delivery in second gravida women.

MATERIAL \& METHODS: We restricted our study to women of parity one with single previous cesarean or single vaginal delivery, as multiple previous cesarean or previous successful vaginal delivery are known to influence the mode of delivery. For comparative analysis, the study population was divided into two groups according to mode of delivery for first birth. Group I ,Pregnant women with cesarean first birth $(n=100)$.Group II, Pregnant women with vaginal first birth $(n=100)$.

RESULTS: In our study the distribution of cases according to age was comparable in both the groups and there was no statistical significant difference ( $p$ value >0.638). The difference which was statistically significant was incidence of placental abnormalities only $(p=0.04)$.

CONCLUSION: To conclude the discussion about obstetric outcomes we observed increased risk of maternal complications and repeat cesarean section following previous cesarean section. About perinatal morbidity and mortality we observed in our study no significant difference in both the groups regarding perinatal outcome.

KEYWORDS: Cesarean deliverey, Vaginal delivery, Gravida, Prenatal.
\end{abstract}

\section{Introduction}

Cesarean section delivery is associated with increased risk of maternal and perinatal morbidities. Cesarean delivery defines the fetus birth via laparotomy and then hysterotomy.
According to $\mathrm{WHO}$, the cesarean section rates are now above $20 \%$ in many countries ${ }^{1}$ and territories, ${ }^{2}$ raising concerns about morbidity in subsequent pregnancies that could be substantial at population level. 
The reasons for the continued increase in the cesarean rates are not completely understood, but some explanations include the following ${ }^{3}$.

Rates of labor induction continue to rise, and induced labor, especially among nulliparas, increases the cesarean delivery rate.

The prevalence of obesity has risen dramatically, and obesity increases the cesarean delivery risk.

Women are having fewer children, thus, a greater percentage of births are among nulliparas, who are at increased risk for cesarean delivery.

The average maternal age is rising, and older women, especially nulliparas, are at increased risk of cesarean delivery.

Most fetuses presenting as breech are now delivered by cesarean. Concern for fetal injury, as well as the infrequency with which a breech presentation meets criteria for a labor trial, almost guarantee that most will be delivered by cesarean section.

The frequency of forceps and vacuum deliveries has decreased.

Rates of cesarean delivery for women with preeclampsia have increased, whereas labor induction rates for these patients have declined.

The use of electronic fetal monitoring is widespread. This technique is associated with an increased cesarean delivery rate compared with intermittent fetal heart rate auscultation. Cesarean delivery performed primarily for "fetal distress" comprises only a minority of all such procedures. In many more cases, concern for an abnormal or "non- reassuring" fetal heart rate tracing lowers the threshold for cesarean delivery.

Malpractice litigations related to fetal injury during spontaneous or operative vaginal delivery continue to contribute significantly to the present cesarean delivery rate.

Data regarding the true incidence of cesarean delivery on maternal request (CDMR) are limited, however, estimates are a 1 to 7 percent rate in the United States in $2003^{4,5}$.

As a broad overview, cesarean delivery has higher maternal surgical risks for the current and subsequent pregnancies. This is balanced against lower rates of perineal injury and short-term pelvic floor disorders. For the neonate, cesarean delivery offers lower rates of birth trauma and stillbirth. Conversely, rates of initial respiratory difficulties are greater with cesarean delivery.

At population level, compared with vaginal delivery in first pregnancy, first birth cesarean delivery has been found to be associated with significantly increased rate of uterine rupture, placenta praevia and placental abruption, placenta praevia leading to peripartum hysterectomy, stillbirth and perinatal death.

Peripartum hysterectomy (for uterine rupture in VBAC) is a marker for significant maternal morbidity and obviously puts an end to a woman's reproductive potential.

The frequency of some maternal complications is increased with all cesarean compared with vaginal deliveries. Villar and associates ${ }^{6}$ in 2007 reported that maternal morbidity rates increased twofold with cesarean compared with vaginal delivery. Principal among these are infection, hemorrhage, and thromboembolism. In addition, anaesthetic complications, which also rarely include death, have a greater incidence with cesarean compared with vaginal delivery ${ }^{7,8}$. Adjacent organs may be injured. The bladder laceration rate is 1 to 3 per 1000 cesarean deliveries, whereas that for ureteral injury approximates 0.3 per 1000 cases $^{9-11}$. Bowel damage occurs in approximately 1 in 1000 cesarean deliveries $^{12}$.

Women who undergo a cesarean delivery are much more likely to be delivered by a repeat operation in subsequent pregnancies.

In second gravida women cesarean delivery is not only attributed to previous cesarean delivery but other feto-maternal conditions may also be responsible for it which may also lead to cesarean section in second gravida women who have undergone vaginal delivery in their first pregnancy. These conditions include dystocia, fetal distress, abnormal presentation, failure of forceps or vacuum etc.

The present study was undertaken to estimate and compare the risk of maternal and perinatal 
morbidity and mortality in second gravida women who have undergone cesarean versus vaginal delivery in their first pregnancy.

\section{Material \& Methods}

This prospective study was conducted in the department of Obstetrics and Gynecology, J.K. Lon Mother \& Child Hospital, Govt. Medical College, Kota during study period of one year from January 2013 to December 2013 after the approval of the hospital's ethical committee.

It included all pregnant women with one previous birth either by cesarean or vaginal route who had not undergone any evacuation, MTP or uterine surgery. We restricted our study to women of parity one with single previous cesarean or single vaginal delivery, as multiple previous cesarean or previous successful vaginal delivery are known to influence the mode of delivery.

For comparative analysis, the study population was divided into two groups according to mode of delivery for first birth.

Group I (case): Pregnant women with cesarean first birth $(n=100)$.

Group II (control): Pregnant women with vaginal first birth $(\mathrm{n}=100)$.

Information obtained on demographic, medical, reproductive history including maternal age, ethnicity, obstetric history, Inter-pregnancy interval (defined as the time passed since the termination of the previous pregnancy and the conception of the next pregnancy), any complication occurring during pregnancy, duration of labor and mode of delivery at time of first birth, perinatal outcomes, educational qualification and type of occupation of patients and their spouses and their family income.

\section{Statistical Analysis}

The data was subjected to statistical analysis by using SPSS software. Student ' $t$ ' test was applied for all quantitative parameters. The means were compared for their statistical difference using $p$ values.
The frequency data was subjected to $\chi^{2}$ test and $\mathrm{p}$ values calculated using SPSS software version 10.0 .

\section{Results}

The present study observed most of the cases were from age group 21-25 years in both the groups (71\% in group 1 and $63 \%$ in group 2) (table 1). In our study show the mode of delivery in group 1 most of the cases (75\%) underwent elective cesarean delivery while in group 2 vaginal delivery was most common (65\%) followed by emergency cesarean (19\%) (table 2).

The most common complications in group 1 were placental abnormality, malpresentation and blood transfusion (10\% each) while in group 2 malpresentation (15\%) was most common complication.

Postpartum haemorrhage was another important complication accounting for about $10 \%$ csases in group 1 and $4 \%$ cases in group 2. Antepartum haemorrhage was present equally in both groups (i.e. $3 \%$ ).

Incidences of maternal complications were more with group 1 patients but the difference between two groups was statistically significant only for placental abnormalities (10\% and 3\% in group 1 and 2 respectively with $p$ value 0.04$)$.

Table 1: Distribution of cases according to age

\begin{tabular}{|l|c|c|c|c|}
\hline \multirow{2}{*}{$\begin{array}{l}\text { Age } \\
\text { years })\end{array}$} & \multicolumn{2}{|c|}{ Group 1 } & \multicolumn{2}{c|}{ Group 2 } \\
\cline { 2 - 5 } & $\begin{array}{l}\text { No of } \\
\text { Cases }\end{array}$ & $\%$ & $\begin{array}{l}\text { No of } \\
\text { Cases }\end{array}$ & $\%$ \\
\hline$\leq 20$ & 2 & 2 & 12 & 12 \\
\hline $21-25$ & 71 & 71 & 63 & 63 \\
\hline $26-30$ & 25 & 25 & 21 & 21 \\
\hline$>30$ & 2 & 2 & 4 & 4 \\
\hline Total & 100 & 100 & 100 & 100 \\
\hline Mean & $24.72 \pm 2.87$ & $24.51 \pm 3.40$ \\
\hline$P$ & \multicolumn{3}{|c|}{0.638} \\
\hline
\end{tabular}


Table 2: Distribution of cases according to Mode of Delivery

\begin{tabular}{|l|c|c|c|c|c|}
\hline \multirow{2}{*}{$\begin{array}{l}\text { Mode of } \\
\text { Delivery }\end{array}$} & \multicolumn{2}{|c|}{ Group 1 } & \multicolumn{2}{c|}{ Group 2 } & \multirow{2}{*}{$\chi^{2} / \mathrm{p}$} \\
\cline { 2 - 6 } & $\begin{array}{c}\text { No. of } \\
\text { cases }\end{array}$ & $\%$ & $\begin{array}{c}\text { No. of } \\
\text { cases }\end{array}$ & $\%$ & \\
\hline Elective LSCS & 75 & 75 & 10 & 10 & $86.450 /<0.001$ \\
\hline $\begin{array}{l}\text { Emergency } \\
\text { LSCS }\end{array}$ & 12 & 12 & 19 & 19 & $1.870 />0.05$ \\
\hline Vaginal & 11 & 11 & 65 & 65 & $61.884 /<0.001$ \\
\hline Forceps & 2 & 2 & 0 & 0 & $2.020 />0.05$ \\
\hline $\begin{array}{l}\text { Assisted } \\
\text { Breech }\end{array}$ & 0 & 0 & 6 & 6 & $6.186 /<0.05$ \\
\hline Total & 100 & 100 & 100 & 100 & \\
\hline
\end{tabular}

Table 3: Distribution of cases according to Maternal Complications

\begin{tabular}{|l|c|c|c|c|c|}
\hline \multirow{2}{*}{ Complications } & \multicolumn{2}{|c|}{ Group 1 } & \multicolumn{2}{c|}{ Group 2 } & $\chi^{2} / \mathrm{p}$ \\
\cline { 2 - 6 } & $\begin{array}{c}\text { No of } \\
\text { cases }\end{array}$ & $\%$ & $\begin{array}{c}\text { No of } \\
\text { cases }\end{array}$ & $\%$ & \\
\hline Preterm Labor & 6 & 6 & 4 & 4 & $0.421 / 0.516$ \\
\hline PIH & 5 & 5 & 6 & 6 & $0.096 / 0.756$ \\
\hline Malpresentation & 10 & 10 & 15 & 15 & $1.14 / 0.28$ \\
\hline APH & 3 & 3 & 3 & 3 & - \\
\hline Placental & 10 & 10 & 3 & 3 & $4.03 / 0.04$ \\
Abnormality & & & & & \\
\hline Blood Transfusion & 10 & 10 & 6 & 6 & $1.08 / 0.29$ \\
\hline PPH & 7 & 7 & 4 & 4 & $0.86 / 0.35$ \\
\hline Hysterectomy & 2 & 2 & 1 & 1 & $0.338 / 0.561$ \\
\hline Uterine rupture & 2 & 2 & 1 & 1 & $0.338 / 0.561$ \\
\hline Bladder Injury & 1 & 1 & 0 & 0 & $1.005 / 0.316$ \\
\hline Wound Infection & 3 & 3 & 2 & 2 & $0.205 / 0.65$ \\
\hline
\end{tabular}

\section{Discussion}

The rising trend of cesarean section is emerging as a major cause of concern for the healthcare system all over the world. The rate of CS has increased dramatically during the last three decades, in some countries to almost one third of all deliveries. The opinion that cesarean section is a better, safer, and less painful way to give birth and the subsequent demand for CS without a medical indication are relatively new.

The reasons for this dramatic rise in cesarean section rate are somewhat complex and newer indications have emerged over the years.

Cesarean section has changed from an operation of direct necessity to one of choice with better maternal result and fetal outcome.

In our present study we tried to analyze the effect of previous cesarean section on current pregnancy and tried to find out the outcome of pregnancy after previous cesarean, how many patients are delivered vaginally after previous cesarean in our institute and what are the obstetrical and perinatal complications associated with previous cesarean section? We have taken a control group comprising cases that had previous birth by vaginal route to compare it with our study group. In our study the distribution of cases according to age was comparable in both the groups and there was no statistical significant difference ( $\mathrm{p}$ value $>0.638$ ).

The age distribution was comparable with the observations in a study ${ }^{13}$ done in 2014 where $92.48 \%$ of patients were from 20-30 year age group.

We observed increased incidence of placental abnormalities, PPH, preterm labor, peripartum hysterectomy, uterine rupture and requirement of blood transfusion in our study group ( group 1) in comparison to control group (group 2), though statistically insignificant except placental abnormalities.

The difference which was statistically significant was incidence of placental abnormalities only ( $\mathrm{p}=0.04)$.

Our observations are comparable with a study ${ }^{14}$ which found that compared with mothers who had primary vaginal births, mothers who had primary cesarean section and underwent labor in the second birth were at increased risk of uterine rupture, peripartum hysterectomy, postpartum hemorrhage (PPH) following vaginal delivery, manual removal of placenta, infection and intensive care unit (ICU) admission.

Another study ${ }^{15}$ observed increased risks for malpresentation (Odds Ratio [OR] 1.84, 95\% Confidence Interval [CI] 1.65-2.06), placenta praevia (OR 1.66, 95\% CI 1.30-2.11), antepartum hemorrhage (OR 1.23, 95\% CI 1.08-1.41), placenta accreta (OR 18.79, 95\% CI 2.28-864.6), prolonged labor (OR 5.89, 95\% CI 3.91-8.89), emergency cesarean (relative risk 9.37, 95\% CI 8.98-9.76) and uterine rupture (OR 84.42, 95\% CI 14.64-infinity).

To conclude the discussion about obstetric outcomes we observed increased risk of maternal 
complications and repeat cesarean section following previous cesarean section. About perinatal morbidity and mortality we observed in our study no significant difference in both the groups regarding perinatal outcome.

\section{Conclusions}

Assessment and comparison of obstetrical and perinatal outcomes after cesarean versus vaginal delivery in second gravida women was done. It is clear from our study that there is increased risk for maternal complications in a previous section pregnancy when compared to a previous vaginal so, efforts should be made to minimize the complications. Patient who have undergone a cesarean section should also be counseled for use of suitable contraceptive methods to increase inter pregnancy interval.

\section{References}

1. Chanrachakul B, Herabutya Y, Udomsubpayakul U. Epidemic of cesarean section at the general, private and university hospitals in Thailand. J Obstet Gynaecol Res 2000; 26: 357-361.

2. Laws PJ, Sullivan EA. Australia's mothers and babies 2002. Perinatal Statistics Series No. 15. Sydney: National Perinatal Statistics Unit, 2004. (AIHW Catalogue No: PER 28).

3. Cunningham F, Leveno $\mathrm{K}$, Bloom $\mathrm{S}$, Hauth J, Rouse D, Spong CY. Cesarean delivery and peripartum hysterectomy. In : Williams Obstetrics, $23^{\text {rd }}$ edition 2011; p544-564.

4. Gossman GL, Joesch JM, Tanfer K. Trends in maternal request cesarean delivery from 1991 to 2004. Obstet Gynecol 2006; 108: 1506.

5. Menacker F, Declercq E, Macdorman MF. Cesarean delivery: background, trends, and epidemiology. Semin Perinatol 2006; 30(5):235.
6. Villar J, Carroli G, Zavaleta N, et al. Maternal and neonatal individual risks and benefits associated with cesarean delivery: multicenter prospective study. BJM 2007; 335:1025.

7. Hawkins JL, Chang J, Palmer SK, et al. Anesthesia-related maternal mortality in the United States: 1979-2002. Obstet Gynecol 2011; 117(1):69.

8. Cheesman K, Brady JE, Flood P, et al. Epidemiology of anesthesia-related complications in labor and delivery, New York State, 2002- 2005. Anesth Analg 2009; 109:1174.

9. Güngördük K, Asicioglu O, Celikkol O, et al. Iatrogenic bladder injuries during cesarean delivery: a case control study. J Obstet Gynaecol 2010; 30(7):667.

10. Phipps MG, Watabe B, Clemons JL, et al. Risk factors for bladder injury during cesarean delivery. Obstet Gynecol 2005; 105(1):156.

11. Rajasekar D, Hall M. Urinary tract injuries during obstetric intervention. $\mathrm{Br} \mathrm{J}$ Obstet Gynaecol 1997; 104:731.

12. Silver RM, Landon MB, Rouse DJ, et al. Maternal morbidity associated with multiple repeat cesarean deliveries. Obstet Gynecol 2006; 107:1226.

13. Wanjari SA. Rising cesarean section rate: a matter of concern? Int $\mathrm{J}$ Reprod Contracept Obstet Gynecol. 2014; 3(3):728-731.

14. Taylor LK, Simpson JM, Roberts CL, Olive EC, Henderson-Smart DJ. Risk of complications in a second pregnancy following cesarean section in the first pregnancy: a population-based study. MJA 2005; 183: 515-519.

15. Kennare R, Tucker G, Heard A, Chan A. Risks of adverse outcomes in the next birth after a first cesarean delivery. Obstet Gynecol. 2007; 109(2 Pt 1):270-6. 